University of Nebraska - Lincoln

DigitalCommons@University of Nebraska - Lincoln

Drought Mitigation Center Faculty Publications Drought -- National Drought Mitigation Center

1995

\title{
Relating United States Crop Land Use to Natural Resources and Climate Change
}

\author{
K. G. Hubbard \\ University of Nebraska-Lincoln, khubbard1@unl.edu \\ F. J. Flores-Mendoza \\ University of Nebraska - Lincoln
}

Follow this and additional works at: https://digitalcommons.unl.edu/droughtfacpub

Part of the Climate Commons, Environmental Indicators and Impact Assessment Commons, Environmental Monitoring Commons, Hydrology Commons, Other Earth Sciences Commons, and the Water Resource Management Commons

Hubbard, K. G. and Flores-Mendoza, F. J., "Relating United States Crop Land Use to Natural Resources and Climate Change" (1995). Drought Mitigation Center Faculty Publications. 164.

https://digitalcommons.unl.edu/droughtfacpub/164

This Article is brought to you for free and open access by the Drought -- National Drought Mitigation Center at DigitalCommons@University of Nebraska - Lincoln. It has been accepted for inclusion in Drought Mitigation Center Faculty Publications by an authorized administrator of DigitalCommons@University of Nebraska - Lincoln. 


\title{
Relating United States Crop Land Use to Natural Resources and Climate Change
}

\author{
K. G. Hubbard and F. J. Flores-Mendoza \\ Department of Agricultural Meteorology, University of Nebraska, Lincoln, Nebraska
}

(Manuscript received 24 June 1993, in final form 30 March 1994)

\begin{abstract}
Crop production depends not only on the yield but also on the area harvested. The yield response to climate change has been widely examined, but the sensitivity of crop land use to hypothetical climate change has not been examined directly. Crop land-use regression models for estimating crop area indices (CAIs) - the percent of land used for corn, soybean, wheat, and sorghum production-are presented. Inputs to the models include available water-holding capacity of the soil, percent of land available for rain-fed agricultural production, annual precipitation, and annual temperature. The total variance of CAI explained by the models ranged from $78 \%$ for wheat to $87 \%$ for sorghum, and the root-mean-square errors ranged from $1.74 \%$ for sorghum to $4.24 \%$ for corn. The introduction of additional climatic variables to the models did not significantly improve their performance.

The crop land-use models were used to predict the CAI for every crop reporting district in the United States for the current climatic condition and for possible future climate change scenarios (various combinations of temperature and precipitation changes over a range of $-3^{\circ}$ to $+6^{\circ} \mathrm{C}$ and $-20 \%$ to $+20 \%$, respectively). The magnitude of climatic warming suggested by GCMs (GISS and GFDL) is from $3.5^{\circ}$ to $5.9^{\circ} \mathrm{C}$ for regions of the United States. For this magnitude of warming, the model suggests corn and soybean production areas may decline while wheat and sorghum production areas may expand. If the warming is accompanied by a decrease in annual precipitation from $1 \%$ to $10 \%$, then the areas used for corn and soybean production could decrease by as much as $20 \%$ and $40 \%$, respectively. The area for sorghum and wheat under these conditions would increase by as much as $80 \%$ and $70 \%$, respectively; the exact amount depending strongly on the change in precipitation. In general, small changes in temperature or precipitation produced larger corresponding changes (on a percentage basis) in soybean, wheat, and sorghum area than in corn area.
\end{abstract}

\section{Introduction}

Both yield and area harvested contribute to total production. Most of the studies on agricultural sensitivity to potential climate change have focused on yield response at a point or in a region (Liverman et al. 1986; Rosenzweig 1990; Easterling et al. 1992). In this study we examine whether the amount of land area used in crop production is itself related to climate. We derive a statistical model to estimate crop geographic distribution in the United States that quantifies, to the extent possible based on input variables, the natural climate and land resources. Climate inputs used in the analysis were long-term averages. Land resources considered were the soil water-holding characteristics and total land area available for farming. Corn, soybean, wheat, and sorghum were selected for study because these crops are well established in major agricultural production areas of the United States.

We also explore possible changes in land use by using the crop land-use model to derive a crop distribution

\footnotetext{
Corresponding author address: Dr. Kenneth G. Hubbard, Department of Agricultural Meteorology, Institute of Agriculture and Natural Resources, 242 L. W. Chase Hall, University of Nebraska, Lincoln, NE 68583-0728.
}

for a number of climate change scenarios. No provision is made in this study for the direct response of crops to $\mathrm{CO}_{2}$ (Rosenberg 1981; Cure and Acock 1986; Idso 1989; Acock 1990), light intensity, nutrient level, or other environmental factors (Bannister 1979; Morison 1988; Norman 1989). Additionally, although the statistical models were formed over a wide range of climate conditions, it is certain that factors not included will contribute to future land-use decisions. All results are presented with these caveats in mind.

\section{Materials and methods}

Annual data on crop production for each of 308 crop-reporting districts (CRDs) in the continental United States were obtained from the U.S. Department of Agriculture (USDA) for the period 1972-1986. From this data, the average land areas devoted to selected crops were developed for each crop-reporting district. For this study, the crop area index (CAI) was defined for each crop as the percent of land usually devoted to that crop. The CAI was calculated by taking a ratio of the average total area harvested for that crop to the total land area and multiplying the result by 100 . All CAIs are for rain-fed conditions. A CAI was developed for each of the crops selected for this study 
(corn, soybean, wheat, and sorghum). The distribution of CAI values in the United States is shown in Figs. 1a-d.

Another variable used in this study was the percent of total land available for crop production in each CRD. This variable was determined from the USDA crop production dataset by summing the fraction of land area devoted to every crop (exclusive of irrigation ) annually and then averaging over the period of record. This variable represents the overall suitability of a CRD for farming.

A single value of available water capacity was used to characterize soils in each district. Elsewhere, a single value was used in larger-scale applications such as calculating drought indices (Palmer 1965) for each climate division and in modeling general circulation where soil water was represented (Milly 1992) at each grid point. A map of the available water capacity by district is given in Main (1979).

Climatological data were taken from the Climatography of the United States No. 20 (NOAA 1985) for the period 1951-1980. The weather station nearest the centroid of each CRD was determined, and values for mean annual temperature, mean total precipitation, mean number of days in the freeze-free period, days with temperature above $32^{\circ} \mathrm{C}\left(90^{\circ} \mathrm{F}\right)$, growing degree days, and days with precipitation greater than $13 \mathrm{~mm}$ ( $0.5 \mathrm{in})$ were tabulated. The units for CAI, percent of land available for rain-fed farming, available water capacity, precipitation, and temperature are CAI (\%), $F$ (\%), $W(\mathrm{~mm}), P(\mathrm{~mm})$, and $T\left({ }^{\circ} \mathrm{C}\right)$.

The model was formed for each crop using multiple linear regression of the form

$$
\begin{aligned}
\mathrm{CAI}_{\text {crop }}=A_{\text {crop }}+B_{\text {crop }, 1} X_{1}+ & B_{\text {crop }, 2} X_{2} \\
& +B_{\text {crop }, 3} X_{3} \cdots .
\end{aligned}
$$

The independent variables $\left(X_{i}\right)$ represent the natural resources of the CRD. Variables were transformed before regression if a nonlinear relationship to CAI was observed.
Actual Corn CAI

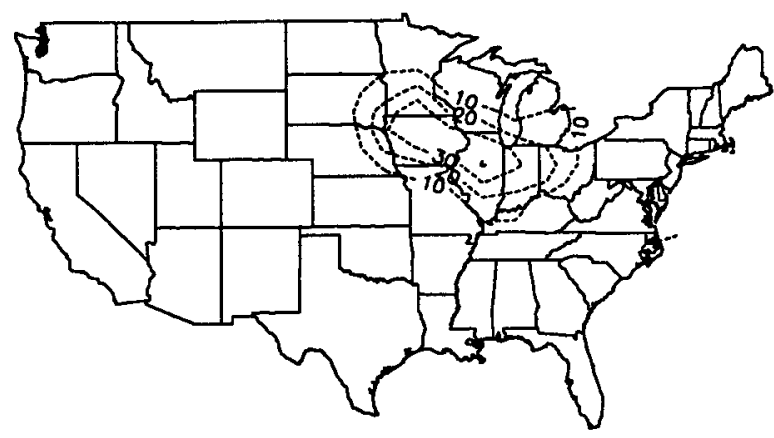

Actual Wheat CAl

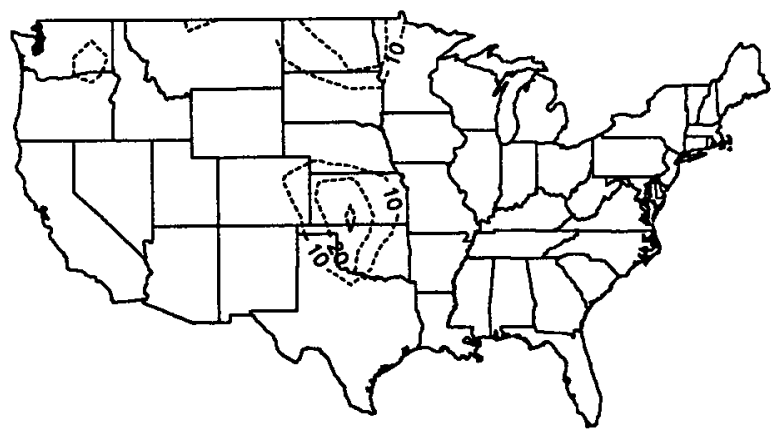

Actual Soybean CA

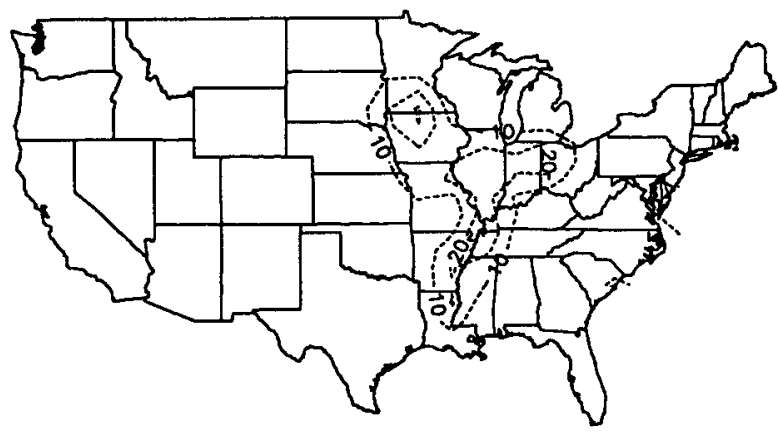

Actual Sorghum CAI

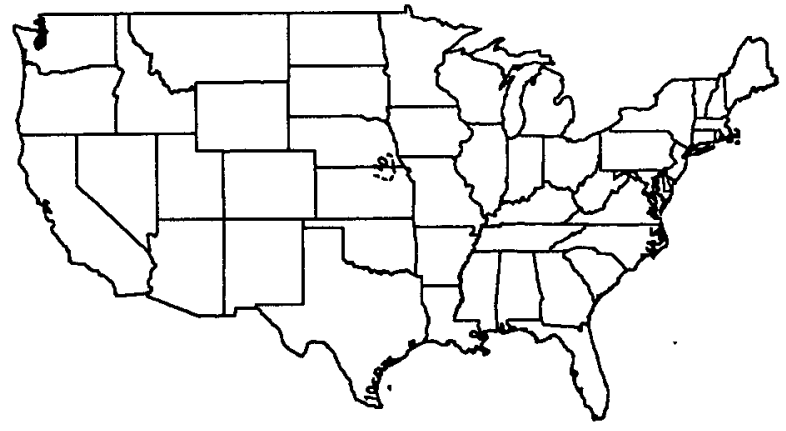

FIG. 1. (a) The average percent of land used for rain-fed corn production ( $\mathrm{CAI}_{\text {corn }}$ ) during the period 1972-1986. (b) The average percent of land used for rain-fed soybean production $\left(\mathrm{CAI}_{\text {soy }}\right)$ during the period 1972-1986. (c) The average percent of land used for rain-fed wheat production $\left(\mathrm{CAI}_{\mathrm{wht}}\right)$ during the period 1972-1986. (d) The average percent of land used for rain-fed sorghum production (CAI $\left.\mathrm{I}_{\text {sorg }}\right)$ during the period 1972-1986. 
Data for each CRD wherein the actual CAI for a crop exceeded $3 \%$ were included in the dataset for that crop. A stepwise process was used to derive the coefficients to be used in (1) for individual crops. First, the available water capacity $(W)$ and the percent of total land available for rain-fed farming $(F)$ were included. Then the temperature $(T)$ and precipitation $(P)$ were added. All climate variables were added one by one to determine if their inclusion significantly increased the proportion of the variance explained $\left(r^{2}\right)$.

Errors in the model estimates could combine in such a way that the resulting total area of predicted land uses would exceed the historically determined area of farmland. To prevent this, we adopted the practice of developing a model for the first crop and diminishing the land potentially available $(F)$ to each subsequent crop for rain-fed farming. The order of model development was arbitrarily chosen as corn, soybean, wheat, and sorghum; subscripts were added to $F$ values for each crop $\left(F_{\text {corn }}=F ; F_{\text {soy }}=F_{\text {corn }}-\mathrm{CAI}_{\text {corn }} ; F_{\text {wht }}\right.$ $=F_{\text {soy }}-\mathrm{CAI}_{\text {soy }} ;$ and $\left.F_{\text {sorg }}=F_{\text {wht }}-\mathrm{CAI}_{\text {wht }}\right)$.

This technique, together with two rules, ensured that the sum of CAI values did not exceed the total land available for farming $\left(\mathrm{CAI}_{\text {corn }}+\mathrm{CAI}_{\text {soy }}+\mathrm{CAI}_{\text {wht }}\right.$ $+\mathrm{CAI}_{\text {sorg }} \leqslant F$ ). First, when the CAI for a given crop exceeded its $F$ value, CAI was set to the $F$ value and CAI values for subsequent crops in that $C R D$ were set to zero. Second, any CAI values below zero were set to zero. Goodness of fit of the model was determined by evaluating the proportion of variance accounted for $\left(r^{2}\right)$ and the root-mean-square error (rmse). We also visually compared the crop patterns formed by model estimates to patterns formed by actual crop land-use data. Maps were produced by plotting contour lines from a field of CAI values placed at the centroid of each of the 308 CRDs. Contour placement was determined by the Kriging technique using Golden Graphics software. ${ }^{1}$

These methods were used to derive CAI values for all four crops in the "no change" scenario (i.e., no change in independent variables). Several "climate change" scenarios were then selected to span the range of changes calculated by a number of numerical global circulation models (GCMs). Regional predictions from the GISS and GFDL models of average annual temperature change and precipitation ratio (future-current) for a doubling of $\mathrm{CO}_{2}$ were previously summarized by Adams et al. (1990) in their study on agricultural productivity. Briefly, regional estimates (and models) of the precipitation ratio ranged from a low of 0.92 (GISS) for the southern Plains to 1.15 (GISS) for the Pacific region. Model differences within a region were from $2 \%$ to $19 \%$. Predicted temperature changes

\footnotetext{
${ }^{1}$ Mention of a manufacturer or vendor name is only for the information of the reader and does not constitute an endorsement of the product over other products.
}

ranged from $3.5^{\circ} \mathrm{C}$ (GISS) in the Southeast to $5.9^{\circ} \mathrm{C}$ (GFDL) in the northern Plains. Prediction differences were as low as zero in the Pacific region to as high as $1.4^{\circ} \mathrm{C}$ in the Southeast.

Climate change scenarios in this study were constructed by pairing various assumed temperature and precipitation changes. Precipitation changes ranged from $-20 \%$ to $20 \%$, and temperature changes ranged from $-3^{\circ}$ to $6^{\circ} \mathrm{C}$. These ranges were chosen to encompass the GCM predictions of precipitation and temperature change discussed above. For a given climate change scenario, the temperature and precipitation were recalculated for all CRDs, and new CAI values were derived. The amount of land used for each crop in the climate change scenario was then compared to the "no change" model estimates of land use to derive the change in land use for each crop. Climate change modelers employ a similar approach in comparing temperature from GCM outputs in "no change" and $\mathrm{CO}_{2}$ doubling scenarios. This technique of comparing two distinct model outputs avoids any systematic differences that may be present between the observed and model values if the observed values were taken as the base values.

\section{Results and discussion}

\section{a. Model development}

The first model was developed for corn. The regression process resulted in the following relationship:

$$
\begin{aligned}
\mathrm{CAI}_{\text {con }}=-23.91 & +0.52 F+0.02 W \\
& +0.01 P+12.32 e^{-0.03(T-10)^{2}} .
\end{aligned}
$$

The $r^{2}$ for this equation was 0.83 and the rmse was 4.24. It was found that addition of climate variables, other than precipitation and temperature, did not significantly increase the variance explained. The temperature term was transformed. The values of CAI were found to be a maximum at mean annual temperatures of $10^{\circ} \mathrm{C}$ and to decrease above or below that value.

Figure la was prepared using the actual $\mathrm{CAI}_{\text {corn }}$ values calculated from crop statistics for each of the 308 CRDs. More than 35\% of the land in parts of Iowa and Illinois is used in rain-fed corn production. The major axis of the crop pattern runs through northwest Iowa and north-central Illinois. CAI values are small outside of the corn belt, with only two areas (not shown) in southern Alabama and from south-central New York to eastern South Carolina having CAIs higher than 5 .

Figure $2 \mathrm{a}$ was prepared using estimated $\mathrm{CAI}_{\text {corn }}$ values from the model represented by (2). The model estimated CAI values above $35 \%$ in both Iowa and Illinois. The estimated CAI values in Fig. 2a drop off in a manner similar to the actual CAI values in Fig. 1a for the states of Wisconsin, Michigan, Ohio, and Kentucky. The estimated CAI extends farther south, however, along the Mississippi River Valley. The model 
Estimated Corn CAl

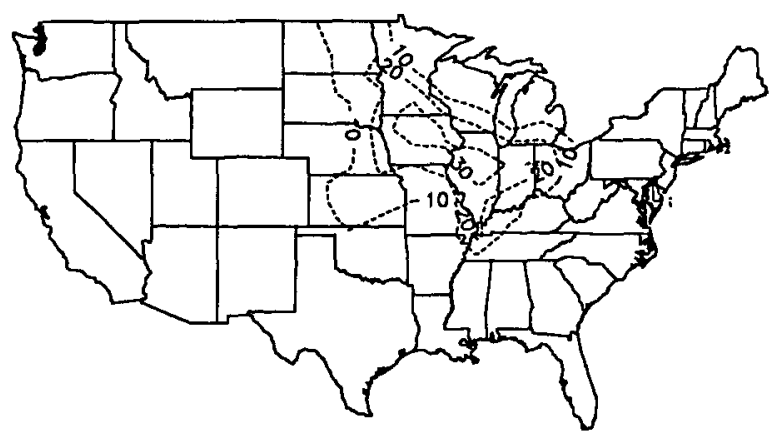

Estimoted Wheat CAI

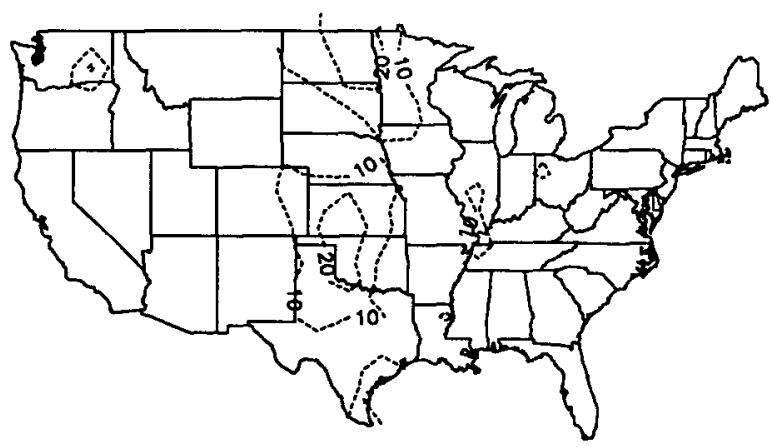

FIG. 2. (a) Estimated $C A I_{\text {corn }}$ (b) Estimated $\mathrm{CAI}_{\text {soy. }}$.
Estimated Soybean CAI

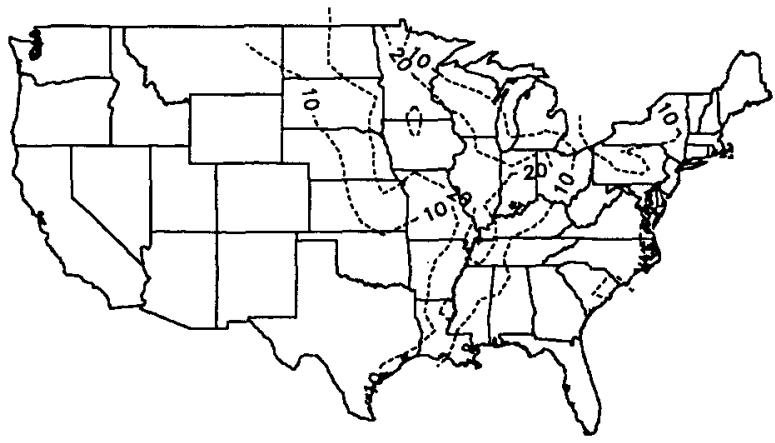

Estimated Sorghum CAI

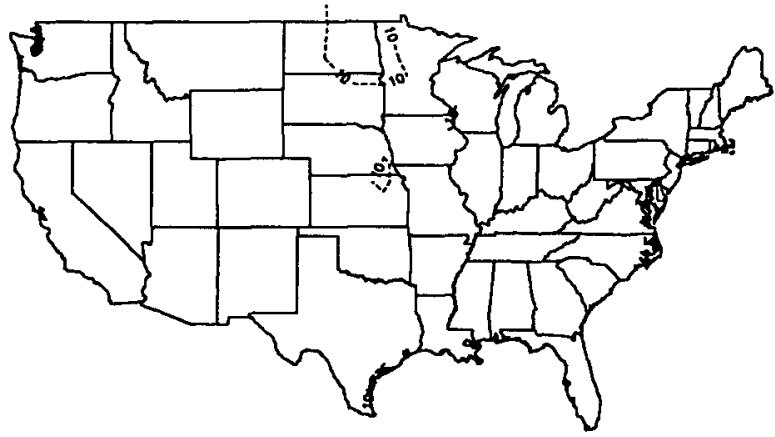

(c) Estimated $\mathrm{CAI}_{\text {wht. }}$ (d) Estimated $\mathrm{CAI}_{\text {sorg. }}$ also produced values of CAI higher than 10 over most of Kansas, the eastern Dakotas, and northwest Minnesota. Contours of CAI less than 10 were omitted because the error, judged by the rmse, was considered to be excessive in that range.

Model development for soybean resulted in the following relationship:

$$
\begin{aligned}
\mathrm{CAI}_{\text {soy }}=2.05+0.698 F_{\text {soy }} & -0.014 W \\
& +0.004 P-0.417 T .
\end{aligned}
$$

The $r^{2}$ for this model was 0.86 and the rmse was 3.04 . There were no transformations of variables.

The actual CAI values for soybean are shown in Fig. 1b. Land used for soybean production is concentrated in two geographical areas. One is located along the Iowa-Minnesota border and the other extends from central Indiana and Illinois down the Mississippi River Valley. The CAI value is still 10 or above in parts of Louisiana. There is considerable overlap in the major areas of land use for corn and soybean.

The estimated CAI for soybean, from (3), appears in Fig. $2 b$. The model estimates an area of $25 \%-30 \%$ along the Minnesota-Iowa border and an area of $25 \%$ in central Illinois. Compared to the actual values of CAI, the model values spread out over more geographical area. For instance, the $10 \%$ contour line for the model estimates (Fig. 2b) encompasses the eastern Dakotas and the eastern portions of Nebraska and Kansas.

The derivation of coefficients for ( 1 ) corresponding to all wheat resulted in the following equation:

$$
\begin{aligned}
\mathrm{CAI}_{\text {wht }}=0.18+0.585 F_{\text {wht }} & -0.008 \mathrm{~W} \\
& -0.028 P+1.611 T .
\end{aligned}
$$

The $r^{2}$ for this equation was 0.78 and the rmse was 3.80 .

The actual CAI values for wheat are shown in Fig. 1c. Areas of concentrated wheat farming appear in Kansas and Oklahoma (CAI values exceed $20 \%$ in much of the area ) and also in North Dakota along the Canadian border (where CAI values exceed $20 \%$ in much of the area). Wheat growing in the Northwest uses more than $10 \%$ of the land in eastern Washington.

Wheat CAI estimates (Fig. 2c) exceed $20 \%$ over much of Kansas and Oklahoma, 20\% along the $\mathrm{Ca}$ nadian border, and $10 \%$ in Washington state. The 
Change (s) U.S. area used for corn production

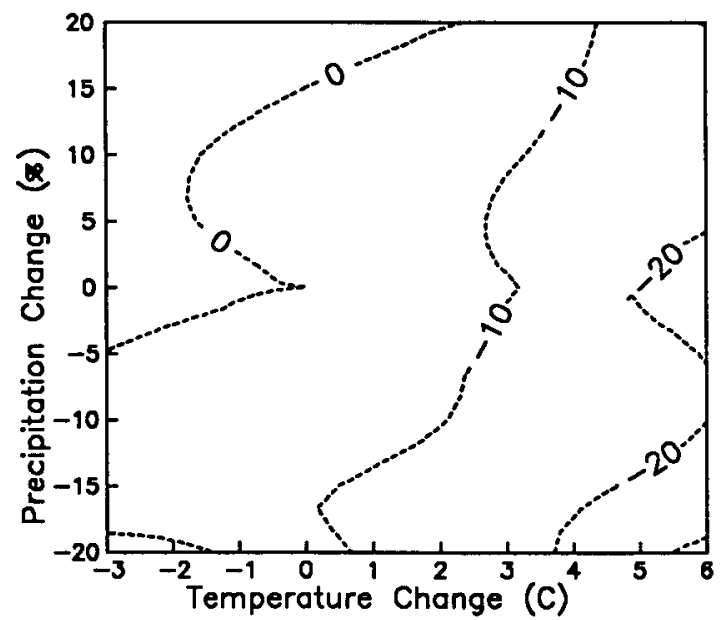

FIG. 3. Predicted change (\%) in land used for corn production in the United States for various precipitation and temperature changes.
Change (s) U.S. area used for soybean production

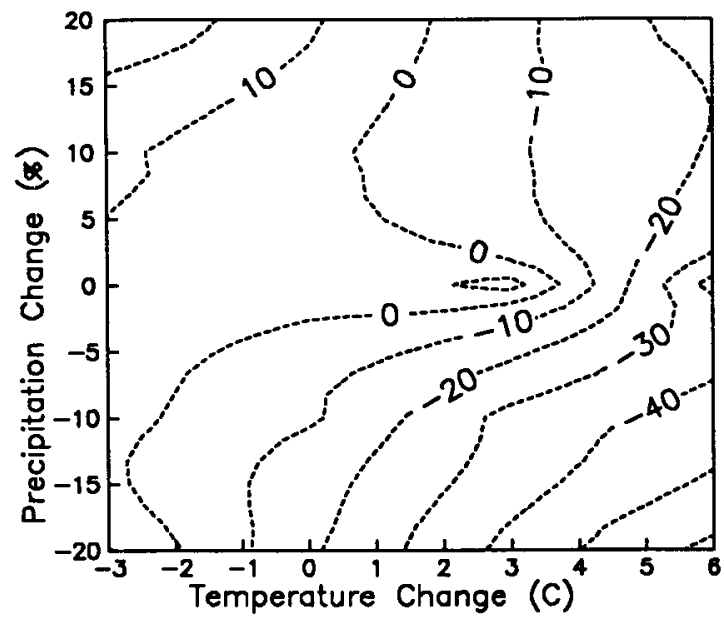

FIG. 4. Predicted change (\%) in land used for soybean production in the United States for various precipitation and temperature changes. model estimates are higher in some instances-for example, in northern Texas, southern Illinois, and parts of South Dakota and Minnesota. The western boundary of the estimated wheat growing area on the Plains closely matches the actual wheat CAI boundary (10\%).

In the case of sorghum, the following equation was derived:

$$
\begin{aligned}
\mathrm{CAI}_{\text {sorg }}=-8.22+0.599 F_{\text {sorg }}+0.026 W \\
+0.0001 P+0.166 T .
\end{aligned}
$$

The $r^{2}$ for this relationship was 0.87 and the rmse was 1.74 .

Actual sorghum CAI values have been plotted in Fig. 1d. CAI values for sorghum indicate that less than $15 \%$ of the land is used in any CRD for sorghum production and that the areas of greatest use are in southeast Texas and in an area centered on the KansasNebraska border.

By applying (5), the estimated CAI values for sorghum were obtained and displayed in Fig. 2d. The two areas of sorghum production mentioned above are present, but an area that exceeds $10 \%$ is formed over eastern North Dakota.

\section{b. Sensitivity to climate change}

The net change in United States land used for corn production (Fig. 3), obtained by determining the difference between the total land in the control and climate change scenarios, is predicted to be negative in most cases. According to the simulation, a precipitation reduction of $15 \%$ and a temperature increase of $3{ }^{\circ} \mathrm{C}$ would result in a $15 \%$ reduction in land used for corn in the United States. The only increases in land used for corn are associated with cooler, wetter scenarios- that is, $1^{\circ}-3^{\circ} \mathrm{C}$ cooling and $15 \%-20 \%$ precipitation increase.

Soybean production area (Fig. 4) is predicted to increase with a $1^{\circ}-4^{\circ} \mathrm{C}$ warming, provided the precipitation does not change by more than a few percent. Otherwise, for warming scenarios, the land area used for soybean production generally decreased. The largest decrease was more than $60 \%$, associated with changes of $6^{\circ} \mathrm{C}$ and $-20 \%$ in temperature and precipitation, respectively. Increases in net soybean production area were observed only in cooler, wetter climate scenarios. The largest increase in area was more than $25 \%$ at $\left(-3^{\circ} \mathrm{C}, 20 \%\right)$.

\section{Change (s) U.S. area used for wheat production}

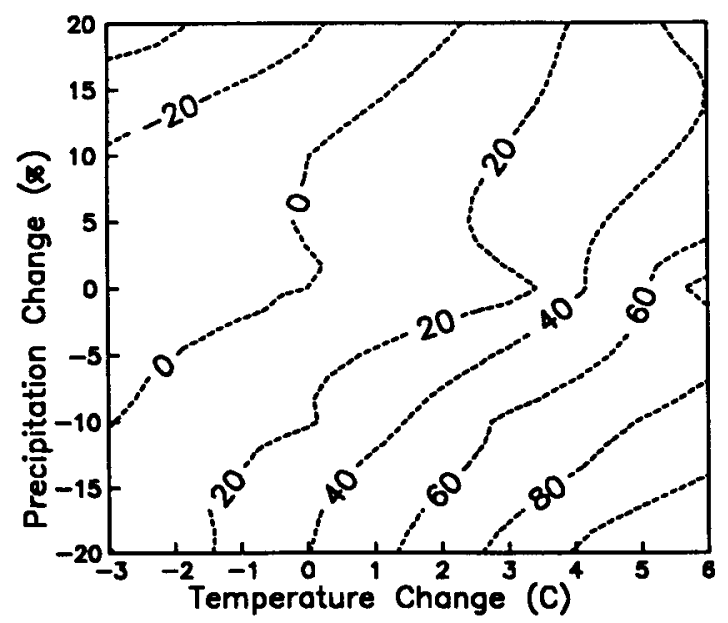

FIG. 5. Predicted change (\%) in land used for wheat production in the United States for various precipitation and temperature changes. 
Land use for wheat (Fig. 5) is estimated to expand, particularly in a warmer, drier climate-the same conditions that lead to decreases in both corn and soybean area. On the other hand, an increase in precipitation accompanied by cooling is estimated to lead to a decrease in wheat area by as much as $50 \%$ at $\left(-3^{\circ}, 20 \%\right)$.

Land area planted to sorghum is predicted to increase under most climate change scenarios (Fig. 6). Barring a climatic cooling, it would appear that land used for sorghum production will stay about the same or increase. Increases up to $70 \%$ are suggested for a warming of $3^{\circ} \mathrm{C}$ and no change in precipitation.

In general, a change in temperature or precipitation produced larger changes (in terms of percentage) in soybean, wheat, and sorghum area than in corn area.

\section{Summary and conclusions}

Models to estimate the current crop geography of corn, soybean, wheat, and sorghum were developed for the United States. Crop production areas overlap considerably in some cases, but a sequential application of the models allowed partitioning of the land available for particular crops. The resulting nested models explain $83 \%, 86 \%, 78 \%$, and $87 \%$ of the variance in corn, soybean, wheat, and sorghum crop patterns, respectively, over the areas where crop production is concentrated (actual CAI > 3\%).

The addition of other climate variables, beyond temperature and precipitation, did not significantly increase the proportion of variance explained. This does not mean that these variables are less important, because the high correlation between average temperature and variables (like average length of frost-free season or growing-degree days) indicates that temperature could be replaced by one of these variables as model input with little change in performance.

The model estimates are similar to the actual values of CAI in the areas where crop production is most concentrated. Of course, data from these areas were used in the development of the models, so this result is basically a confirmation of the high correlation between CAI and the independent variables. The model produced some fairly large CAI values outside of the current areas of production. There are several possible explanations for this. Current model inputs may not represent factors that prohibit successful crop production in these areas. It is certainly possible that diseases, pests, and/or climate conditions on a growing season (or shorter) timescale may be important in further refining the crop land-use models in these areas.

Similarly, it is also unclear why CAI models sometimes indicated no difference between regions that produce dissimilar crops. For instance, more than $10 \%$ of the land in northern Missouri is used in corn production. The model values agree closely with this number. The model also predicts $10 \%$ of the area in much of Kansas, however, where actual CAI values are all less.
Change (x) U.S. area used for sorghum production

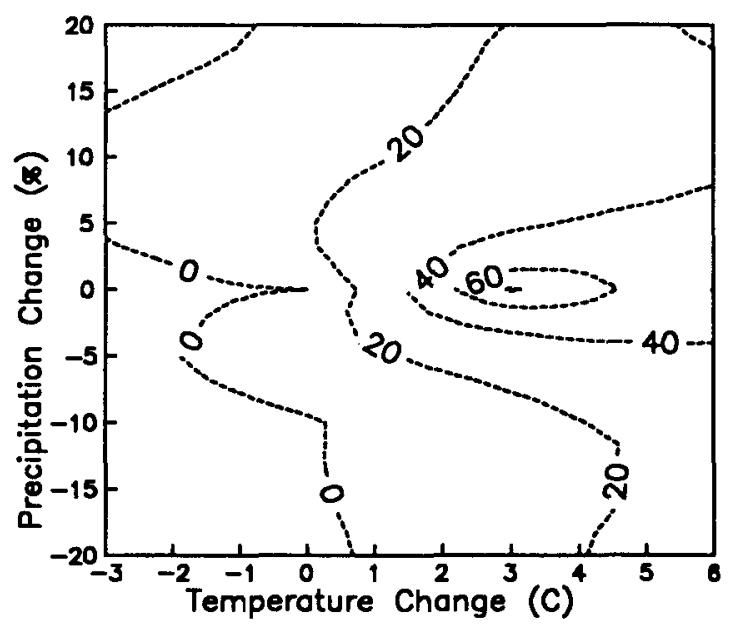

FIG. 6. Predicted change (\%) in land used for sorghum production in the United States for various precipitation and temperature changes.

This supports the notion that the climate, soils, and available farm land (taken as a whole) are not significantly different in Kansas. It may be that technical limitations exist in Kansas. The momentum of past agricultural investment choices for farm equipment, transportation, and storage facilities may dictate the crops that are produced. For these or other reasons, the performance of the four crops is probably not limited to only those areas where they are now grown. The implications of this to climate change are important and may point to a need to integrate economical and societal issues into further studies.

For the magnitude of climatic warming suggested by $\operatorname{GCMs}\left(3.5^{\circ}-5.9^{\circ} \mathrm{C}\right)$, the following conclusions are suggested by the results of this study. Corn and soybean production areas are predicted to decline while wheat and sorghum production areas will expand. If the warming is accompanied by a decrease in annual precipitation from $1 \%$ to $10 \%$, then the areas used for corn and soybean production could decrease by as much as $20 \%$ and $40 \%$, respectively. The area for sorghum and wheat under these conditions may increase by as much as $80 \%$ and $70 \%$, respectively, the exact amount depending strongly on the change in precipitation.

Regression models may perform poorly in situations that require extrapolation, so results from these models should be viewed as a sensitivity analysis in applications where the input conditions are outside the range of conditions used in deriving the models.

Acknowledgments. This research was supported in part by grant NA87AA-D-CP112 from the National Oceanic and Atmospheric Administration, U.S. Department of Commerce. Mr. Francisco Flores-Mendoza was supported by the Consejo Nacional de Ciencia y Tecnologia (CONACyt) of Mexico. 


\section{REFERENCES}

Acock, B., N. J. Rosenberg, and L. H. Allen Jr., 1990: Effects of carbon dioxide on photosynthesis, plant growth, and other processes. Impact of Carbon Dioxide, Trace Gases, and Climate Change on Global Agriculture, B. A. Kimball, N. J. Rosenberg, and L. H. Allen Jr., Eds., American Society of Agronomy Special Publication 53, 45-60.

Adams, R. M., C. Rosenzweig, R. M. Peart, J. T. Ritchie, B. A. McCarl, J. D. Blyer, R. B. Curry, J. W. Jones, K. J. Boote, and L. H. Allen, Jr., 1990: Global climate change and U.S. agriculture. Nature, 345, 219-224.

Bannister, P., 1979: Introduction to Physiological Plant Ecology. John Wiley \& Sons, $273 \mathrm{pp}$.

Cure, J. D., and B. Acock, 1986: Crop responses to carbon dioxide doubling: A literature survey. Agri. Forest Meteor., 38, 127-145.

Easterling, W. E., N. J. Rosenberg, M. S. McKenney, and C. A. Jones, 1992: An introduction to the methodology, the region of the study, and a historical analog of climate change. Agric. Forest Meteor., 59, 3-15.

Idso, S. B., 1989: Carbon dioxide, soil moisture, and future crop production. Soil Sci., 147, 305-307.
Liverman, D. M., W. H. Terjung, J. T. Hayes, and L. O. Mearns, 1986: Climatic change and grain corn yields in the North American Great Plains. Clim. Change, 9, 327-347.

Main, W. A., 1979: Palmer index computations for small land areas. 14th Conf. on Agriculture and Forest Meteorology, Minneapolis, MN, Amer. Meteor. Soc., 150-153.

Milly, P. C. D., 1992: Potential evaporation and soil moisture in general circulation models. J. Climate, 5, 209-226.

Morison, J. I. L., 1988: Effect of increasing atmospheric $\mathrm{CO}_{2}$ on plants and their responses to other pollutants, climatic and soil factors. Aspects Appl. Biol., 17, 113-122.

NOAA, 1985: Climatography of the U.S. No. 20. National Climatic Data Center, U.S. Department of Commerce.

Norman, J. M., 1989: Synthesis of canopy processes. Plant Canopies: Their Growth, Form and Function, G. Russell, B. Marshall, and P. G. Jarvis, Eds., Cambridge University Press, 178 pp.

Palmer, W. C., 1965: Meteorological drought. Research Paper No. 45 , U.S. Weather Bureau, $58 \mathrm{pp}$.

Rosenberg, N. J., 1981: The increasing $\mathrm{CO}_{2}$ concentration in the atmosphere and its implication on agricultural productivity. Clim. Change, 3, 265-279.

Rosenzweig, C., 1990: Crop response to climate change in the Southern Great Plains: A simulation study. Prof. Geo., 42, 20-37. 